\title{
A study on Happiness and Quality of Life based on Smoking Status
}

\author{
Anjali Majeethia ${ }^{1}$, Neha Bhansali ${ }^{2}$ \\ ${ }^{1}$ Post Graduate Student \\ ${ }^{2}$ Assistant Professor \\ Department of Psychology, Maniben Nanavati Women's College, Mumbai \\ E-mail-nehabans84@gmail.com \\ Corresponding Author - Neha Bhansali
}

\begin{abstract}
Introduction: The purpose of the study is to compare the level of Happiness and Quality of Life in smokers, ex-smokers and non-smokers. The study is important in identifying the level of happiness and Quality of life in smokers, non-smokers and ex-smokers. Tobacco use in for of cigarettes is highly prevalent in India especially in corporate and service sector. This study also provided an insight as to how status of smoking can affect level happiness and Quality of life of a person.

Methodology: 55 participants working in corporate sector were purposively selected from Mumbai region. The participants were required to fill a consent form prior to the administration of the tests. The researcher provided information to the participants about the principle of confidentiality and each participant was assigned a code number to keep their identity confidential. The data was collected using the survey method. Oxford Happiness Scale and World Health Organization Quality of Life (WHOQOL)-BREF were administered on each participant.

Result: The first research question was that happiness will be higher in ex-smokers than smokers. The statistical result obtained was in line with the hypothesis and also in line with previous studies. No significant difference was found between ex-smoker and non-smoker and between smoker and nonsmoker. This result could be because smokers experience temporary reduction in stress which can result in increase of happiness.

Conclusion: The findings indicate the ex-smokers have high level of happiness than smokers. It was also found that Quality of life in psychology domain is higher in ex-smoker compared to smokers.
\end{abstract}

Keywords: Smokers, Non-smokers, happiness, quality of life.

(Paper received $-22^{\text {nd }}$ June 2017 , Peer review completed $-24^{\text {th }}$ July 2017 , Accepted $-30^{\text {th }}$ July 2017)

\section{INTRODUCTION}

Smoking has been common in our country since a long time. Tobacco was introduced in India in $17^{\text {th }}$ century which than merged with the tradition smoking patterns. As time passed various ways to consume tobacco were introduced. Most common form of tobacco consumption nowadays is cigarette smoking. India has over 100 million adult smokers, the second highest number of smokers in the world after China. There are already about 1 million adult deaths per year from smoking. India is the second largest consumer of tobacco globally, and accounts for approximately one-sixth of the world's tobacco-related deaths. The tobacco problem in India is peculiar, with consumption of variety of smokeless and smoking forms [1]. 


\section{Happiness}

The theory of Authentic Happiness is that happiness could be analyzed into three different elements that we choose for their own sakes: positive emotion, engagement, and meaning. And each of these elements is better defined and more measurable than happiness [2]. Operationally, one might define a person's chronic happiness level in terms of his or her retrospective summary judgments regarding his or her mood and satisfaction during some recent period (such as the past 2,6 , or 12 months) or as the average of momentary judgments of mood and satisfaction made at several times during the selected period. It is worth adding, however, that people may vary in their hedonic profiles, such that two individuals with similar chronic happiness levels might differ in their relative levels of contentment with life versus their relative frequency of experiencing positive and negative mood states. The Sustainable Happiness Model focuses on three primary types of factors that causally affect the chronic happiness level, namely, the set point, life circumstances, and intentional activity [3].

\section{Quality of Life}

Based on the notion of perfectionist happiness, Lane [4] developed a theory of quality of life. He defined quality of life (QOL) as a relation between a person's subjective and objective sets of circumstances. The subjective set of a person with high QOL involves nine elements: capacity for enjoying life, cognitive complexity, a sense of autonomy and effectiveness, self-knowledge, self-esteem, ease of interpersonal relations, ethical orientation, personality integration and productivity orientation. According to Lane, when these elements are combined they are responsible for a sense of subjective-well-being and societal development. Lane calls this subjective set - quality of the person or (QP). The objective self reflects the quality of the environmental condition (QC) which represents opportunities for the person to achieve $\mathrm{QP}$.

The nine objective sets are: adequate material support, physical safety and security, available friends and social support, opportunities for the expression and receipt of love, opportunities for intrinsically challenging work, leisure opportunities that have elements of skill, creativity and relaxation available set of moral values that can give meaning to life, opportunities for self-development and a justice system that is managed by disinterested and competent parties. Therefore, $\mathrm{QOL}=\mathrm{f}(\mathrm{QP}, \mathrm{QC})$ or the quality of life (QOL) of a person is a function of both the quality of his character (QP) and the environmental conditions surrounding him (QC) [5].

\section{Smoking, Happiness and Quality of Life}

A cross sectional study was conducted to find differences in happiness between smokers, ex-smokers and never smokers. A nationally representative sample of 6923 adults were taken to examine the association between smoking status (never smoker, smoker, ex-smoker $<1$ year, ex-smoker $\geq 1$ year) and two standard measures of happiness adjusting for socio demographic characteristics. The results indicate that exsmokers who have stopped for a year or more are happier than current smokers and similar to never smoker [6]. A study to investigate the cross-sectional association between smoking and happiness in 4553 randomly sampled Chinese adults in Hong Kong. Telephone surveys were conducted between 2009 and 2012. Happiness was measured using the four-item Subjective Happiness Scale (SHS) and single-item Global Happiness Item (GHI). Smoking status was categorized as current smokers, ex-smokers (quit for > 6 months) and never smokers. It was found that Ex-smokers in Hong Kong are happier than current smokers and never smokers [7].

Another study was conducted to contribute to the empirical debate on whether quitting smoking decreases happiness by analyzing the subjective ratings of life satisfaction, or 'happiness' of current smokers, exsmokers, and permanent non-smokers from a large high-quality panel survey of over 5000 randomly selected adults from 2007 to 2013 in the Netherlands. They found that those who have quit smoking are statistically significantly happier than those who are still smoking, and are at least as happy as those who have never smoked [8]. A study was done to measure subjective happiness and health behaviour among a sample of university students in India. A cross-sectional survey was done to assess happiness and health behaviour among a sample of 800 randomly selected university students. They found that better social support, better personal mastery, normal sleep duration, no current tobacco use, and eating breakfast daily or almost daily were associated with happiness [9]. 
Piper and others [10] did a study on Smoking Cessation and Quality of Life by measuring the life satisfaction of quitters and smokers over three years in a sample of 1504 smokers enrolled in a smoking cessation trial. The aim of the study was to determine the relation between smoking cessation and subjective measures of well-being, including global quality of life (QOL), health-related QOL (HR-QOL), affect, relationship satisfaction, and stressor occurrence. The results show Compared with continuing smokers, quitters showed improved global QOL, HR-QOL, and affect at years 1 and 3 and fewer stressors by year $3[10]$.

A cross-sectional study on Happiness and Smoking Cessation among parents was done to determine if parental smoking cessation is associated with increased happiness and to identify characteristics of parental quitters who experience increased happiness. A total of 1,355 parents completed a 12-month follow-up interview and it was found that parents who quit smoking reported being happier than parents who did not quit [11]. A study was conducted with the aim to assess the difference in health status between current smokers and ex-smokers of five years or greater standing. 3000 adults (1500 smokers, 1500 exsmokers) randomly selected from the records of nine general practices were each sent a postal questionnaire containing SF-36, EuroQol, condition-specific and socio demographic questions. Results showed that smoking cessation leads to an improvement in a range of respiratory symptoms and healthrelated quality of life [12].

A study was done on whether smokers who enrolled in a community-based smoking cessation program and were successful in quitting for a six-month period had better health-related quality-of-life at six months relative to those who relapsed. An observational, longitudinal design was used; the sample included 350 participants 18-65 years of age. Health-related quality-of-life was measured using a broad array of indicators of physical and mental health. Six-month outcomes were compared between successful quitters and relapses using analysis of covariance. Those who quit for six months had better psychological wellbeing, cognitive functioning, energy/fatigue, sleep adequacy, self-esteem, sense of mastery, and worse role functioning at six months than those who continued to smoke [13].

A study was conducted to study the Dynamics of smoking cessation and health-related quality of life among Canadians. Data was collected from nine cycles (1994/1995 through 2010/2011) of the National Population Health Survey. An analysis was done based on longitudinal data for 3,341 men and 4,143 women aged 40 or older in 1994/1995. It was found that across all ages and for both sexes, persistent smokers had lower HRQL than did never-smokers and at any age, and for both men and women, long term smoking cessation results in improvements in HRQL [14].

A study was done to see the relation between smoking status, nicotine dependence and happiness in nine countries of former Soviet Union. Data was taken from a cross-sectional population-based study undertaken in 2010/2011 in Armenia, Azerbaijan, Belarus, Georgia, Kazakhstan, Kyrgyzstan, Moldova, Russia and Ukraine. Information was collected from 18000 respondents aged $\geq 18$ on smoking status (never, ex-smoking and current smoking), cessation attempts and nicotine dependence. From the pooled country analyses it was found that never smokers and ex-smokers were both significantly happier than current smokers. Smokers with higher levels of nicotine dependence were significantly less happy than those with a low level of dependence [15].

A study was conducted to investigate change in mental health after smoking cessation compared with continuing to smoke. 26 studies that assessed mental health with questionnaires designed to measure anxiety, depression, mixed anxiety and depression, psychological quality of life, positive affect, and stress were included. Follow-up mental health scores were measured between seven weeks and nine years after baseline. It was found that anxiety, depression, mixed anxiety and depression, and stress significantly decreased between baseline and follow-up in quitters compared with continuing smokers. Both psychological quality of life and positive affect significantly increased between baseline and follow-up in quitters compared with continuing smokers. Thus, results prove that smoking cessation is associated with reduced depression, anxiety, and stress and improved positive mood and quality of life compared with continuing to smoke [16].

Research was conducted to study the relations among meaning in life, depression, anxiety, and social support with self-reported general health among smoking cessation patient. Ninety-nine smoking cessation group patients completed questionnaires. Results show that propensity to seek meaning in life was the only 
psychosocial correlate of people's perceived social benefits of health care utilization [17]. The purpose of the study is to compare the level of Happiness and Quality of Life in smokers, ex-smokers and nonsmokers. The study should be important in identifying the level of happiness and Quality of life in smokers, non-smokers and ex-smokers.

\title{
METHODOLOGY
}

\author{
Hypotheses \\ Hypothesis 1- Happiness will be higher in ex-smokers than smokers \\ Hypothesis 2- Quality of life will be higher in ex-smokers than smokers
}

\section{Participants}

The sample consisted of 55 young adults (18 to 35 years) who were working in corporate sector. Participants of both genders were included. Data to measure status of smoking was collected from 20 smokers, 20 non-smokers and 15 ex-smokers. Data was collected from the young adults working in the corporate sector of Mumbai region. Snowball sampling method was used for collecting the data. Participants consuming substance other than cigarettes or alcohol were excluded.

The proposed research was a survey design using questionnaires.

\section{Instruments}

1. Oxford Happiness Questionnaire [18].

2. The World Health Organization Quality of Life (WHOQOL)-BREF [19].

55 participants working in corporate sector were purposively selected from Mumbai region. The participants were required to fill a consent form prior to the administration of the tests. The researcher provided information to the participants about the principle of confidentiality and each participant was assigned a code number to keep their identity confidential. The data was collected using the survey method. Oxford Happiness Scale and World Health Organization Quality of Life (WHOQOL)-BREF were administered on each participant. The standardized instructions were provided before the administration. The proposed research aims at finding that whether happiness and quality of lifepsychology domain is high in ex-smokers and non-smokers than smokers. A number was assigned to each participant so that the personal identity could not be revealed. Consent forms were given to all the individuals who become the part of the research.

\section{STATISTICAL ANALYSIS}

The result of the collected data was quantitatively analyzed. There is one independent with three levels (smoker, non-smoker and ex-smoker) and two dependent variables (happiness and quality of life psychology domain), hence the inferential statistics used was two one way ANOVA. The analysis of the data was carried out using Statistical Package for Social Sciences (SPSS student 14 days trial version).

\section{RESULTS}

The descriptive statistics for dependent variable happiness, revealed that for first level of independent variable which is smoker the mean value is 120.85 with the standard deviation of 16.040 and variance of 257.292. The maximum attainable score on oxford happiness scale is 174 and minimum attainable score is 29. The score of happiness ranged from 88 to 157 for smokers. Skewness and kurtosis values were examined on the total population to check the normality of dependent variable. The statistics was -0.057 for skewness and 0.427 for kurtosis for smokers.

For the second level of independent variable which is non-smoker the mean value is 129.75 with the standard deviation of 13.954 and variance of 194.724. The maximum attainable score on oxford happiness scale is 174 and minimum attainable score is 29 . The score of happiness ranged from 103 to 157 for 
smokers. Skewness and kurtosis values were examined onthe total population to check the normality of dependent variable. The statistics was 0.045 for skewness and -0.053 for kurtosis for smokers.

For the third level of independent variable which is ex-smoker the mean value is 132.93 with the standard deviation of 13.488 and variance of 181.924 . The maximum attainable score on oxford happiness scale is 174 and minimum attainable score is 29 . The score of happiness ranged from 110 to 155 for smokers. Skewness and kurtosis values were examined on the total population to check the normality of dependent variable. The statistics was 0.041 for skewness and -0.905 for kurtosis for smokers.

The descriptive statistics for dependent variable Quality of Life-psychological domain (psyQOL), revealed that for first level of independent variable which is smoker the mean value is 61.70 with the standard deviation of 8.554 and variance of 73.168. The maximum attainable transformed score on psychological domain of WHO quality of life scale is 100 and minimum attainable score is 0 . The score of psyQOL ranged from 44 to 69 for smokers. Skewness and kurtosis values were examined on the total population to check the normality of dependent variable. The statistics was -0.672 for skewness and -1.016 for kurtosis for smokers.

For the second level of independent variable which is non-smoker the mean value is 65.40 with the standard deviation of 9.196 and variance of 84.568. The maximum attainable transformed score on psychological domain of WHO quality of life scale is 100 and minimum attainable score is 0 . The score of psyQOL ranged from 44 to 81 for smokers. Skewness and kurtosis values were examined on the total population to check the normality of dependent variable. The statistics was -0.382 for skewness and 0.272 for kurtosis for smokers.

For the third level of independent variable which is ex-smoker the mean value is 79.60 with the standard deviation of 9.575 and variance of 91.686 . The maximum attainable transformed score on psychological domain of WHO quality of life scale is 100 and minimum attainable score is 0 . The score of psyQOL ranged from 63 to 94 for smokers. Skewness and kurtosis values were examined on the total population to check the normality of dependent variable. The statistics was -0.323 for skewness and 0.346 for kurtosis for smokers (Table 1).

Referring to the table 3 the obtained $F$ value is 3.334 which is significant at 0.05 levelFor Tukey's HSD, a significant difference was found between ex-smoker and smoker (at 0.05 level) for level of happiness. No significant difference was found between ex-smoker and non-smoker and between smoker and nonsmoker. The test between subjects' effect for dependent variable- Quality of Life revealed an $\mathrm{F}$ value $=$ 17.900 which was significant at 0.0001 level (Table 1).

Table 1 - Scores on the various scales across both the groups

\begin{tabular}{|c|c|c|c|c|c|}
\hline \multirow{2}{*}{ Scale Used } & Smoker & Non Smoker & Ex-Smoker & ANOVA & p value \\
\cline { 2 - 5 } & $120.8 \pm 16.04$ & $129.74 \pm 13.95$ & $132.48 \pm 13.48$ & 3.334 & $0.043^{*}$ \\
\hline $\begin{array}{c}\text { Oxford Happiness } \\
\text { Scale }\end{array}$ & $61.7 \pm 8.55$ & $65.4 \pm 9.19$ & $79.6 \pm 9.5$ & 17.9 & $0.0001^{*}$ \\
\hline $\begin{array}{c}\text { WHO Quality of } \\
\text { Life BREF }\end{array}$ & & & & \\
\hline
\end{tabular}

Statistics is done using One Way ANOVA $\left(\mathrm{p}<0.05=\right.$ significant $\left.^{\star}\right)$

\section{DISCUSSION}

The first research question was that happiness will be higher in ex-smokers than smokers. The statistical result obtained was in line with the hypothesis and also in line with previous studies. No significant difference was found between ex-smoker and non-smoker and between smoker and non-smoker. This result could be because smokers experience temporary reduction in stress which can result in increase of happiness. 
A cross sectional study was done to find differences in happiness between smokers, ex-smokers and never smokers. A nationally representative sample of 6923 adults were taken to examine the association between smoking status (never smoker, smoker, ex-smoker $<1$ year, ex-smoker $\geq 1$ year) and two standard measures of happiness adjusting for socio demographic characteristics. The results indicate that ex-smokers who have stopped for a year or more are happier than current smokers and similar to never smoker [20].

A study was conducted to contribute to the empirical debate on whether quitting smoking decreases happiness by analyzing the subjective ratings of life satisfaction, or 'happiness' of current smokers, exsmokers, and permanent non smokers from a large high-quality panel survey of over 5000 randomly selected adults from 2007 to 2013 in the Netherlands. They found that those who have quit smoking are statistically significantly happier than those who are still smoking, and are at least as happy as those who have never smoked [21].

The second research question was Quality of life will be higher in ex-smokers than smokers. The statistical result found was in line with the second hypothesis and also in line with past studies. No significant difference was found between smoker and non-smoker.

A study was done to examine the relationship between cigarette smoking and self-reported physical and mental functional status. It was a cross-sectional survey of 837 patients visiting 2 family practice centers. Patients completed a self-administered survey about physical and mental functional status, as measured by the SF-36. Data on current and former cigarette use and demographic variables (age, gender, education, income) was taken. Results showed that Current smokers reported lower functional status than nonsmokers, in physical and especially in mental domains [22].

A study conducted to measure perception of health amongst ever-smokers and never-smokers. A comparison was done using the SF-36 Health Survey Questionnaire and a variety of questions on lifestyle. For the study 1200 adults, aged 20-89 years were randomly selected from South Sales, UK. Results indicated that ever smokers had a significantly worse health experiences in the four of the eight parameters measured by the SF-36 [23].

\section{CONCLUSION}

The purpose of the study is to compare the level of Happiness and Quality of Life in smokers, ex-smokers and non-smoker. The findings indicate the ex-smokers have high level of happiness than smokers. It was also found that Quality of life in psychology domain is higher in ex-smoker compared to smokers.

\section{REFERENCES}

1. Jindal SK, Aggarwal AN, Chaudhry K, Chhabra SK, D Souza GA, Gupta D, Katiyar SK, Kumar R, Shah B, Vijayan VK. Tobacco smoking in India: prevalence, quit-rates and respiratory morbidity. Indian J Chest Dis Allied Sci 2006;48(1):37-44.

2. Seligman ME. Authentic happiness: Using the new positive psychology to realize your potential for lasting fulfillment. Simon and Schuster; 2004.

3. Lyubomirsky S, Sheldon KM, Schkade D. Pursuing happiness: The architecture of sustainable change. Rev Gen Psychol 2005;9(2):111-22.

4. Lane SD, Cherek DR, Tcheremissine OV, Steinberg JL, Sharon JL. Response perseveration and adaptation in heavy marijuana-smoking adolescents. Addict Behav 2007;32(5):977-90.

5. Sirgy MJ. Consequences of Hedonic Well-Being, Life Satisfaction, and Eudaimonia. InThe Psychology of Quality of Life 2012 (pp. 45-60). Springer Netherlands.

6. Shahab L, McEwen A. Online support for smoking cessation: a systematic review of the literature. Addiction 2009;104(11):1792-804.

7. Preston SH, Wang H. Sex mortality differences in the United States: The role of cohort smoking patterns. Demography 2006;43(4):631-46.

8. Veenhoven R. Healthy happiness: Effects of happiness on physical health and the consequences for preventive health care. J Happiness Stud 2008;9(3):449-69.

9. Christakis NA, Fowler JH. The collective dynamics of smoking in a large social network. New Eng J Med 2008;358(21):2249-58 
10. Piper ME, Kenford S, Fiore MC, Baker TB. Smoking cessation and quality of life: changes in life satisfaction over 3 years following a quit attempt. Ann Behav Med 2012;43(2):262-70.

11. Drehmer JE, Hipple B, Ossip DJ, Nabi-Burza E, Winickoff JP. A Cross-Sectional Study of Happiness and Smoking Cessation Among Parents. J Smoking Cess 2015;3:1-9.

12. Sarna L, Bialous SA, Cooley ME, Jun HJ, Feskanich D. Impact of smoking and smoking cessation on health-related quality of life in women in the Nurses' Health Study. Qual Life Res 2008;17(10):1217-27.

13. McCann SJ. Subjective well-being, personality, demographic variables, and American state differences in smoking prevalence. Nicot Tobacc Res 2010;12(9):895-904.

14. Breslin G, Nevill AM, Donnelly P, Murphy MH. Socio-demographic and behavioural differences and associations with happiness for those who are in good and poor health. Int J Happiness Dev 2013;1(2):14254.

15. Stickley A, Koyanagi A, Roberts B, Leinsalu M, Goryakin Y, McKee M. Smoking status, nicotine dependence and happiness in nine countries of the former Soviet Union. Tobacc Contr 2015;24(2):190-7.

16. Daniel M, Cargo MD, Lifshay J, Green LW. Cigarette smoking, mental health and social support: data from a northwestern First Nation. Can J Pub Health 2004;1:45-9.

17. Mykletun A, Overland S, Aarø LE, Liabø HM, Stewart R. Smoking in relation to anxiety and depression: evidence from a large population survey: the HUNT study. Eur Psychiatry 2008;23(2):77-84.

18. Hills P, Argyle M. The Oxford Happiness Questionnaire: A compact scale for the measurement of psychological well-being. Personal Individ Diff 2002;33(7):1073-82.

19. Skevington SM, Lotfy M, O'Connell KA. The World Health Organization's WHOQOL-BREF quality of life assessment: psychometric properties and results of the international field trial. A report from the WHOQOL group. Qual Life Res 2004;13(2):299-310.

20. Fidler JA, Shahab L, West O, Jarvis MJ, McEwen A, Stapleton JA, Vangeli E, West R. 'The smoking toolkit study': a national study of smoking and smoking cessation in England. BMC Pub Health 2011;11(1):479.

21. Steptoe A, Wardle J, Cui W, Bellisle F, Zotti AM, Baranyai R, Sanderman R. Trends in smoking, diet, physical exercise, and attitudes toward health in European university students from 13 countries, 1990-2000. Prev Med 2002;35(2):97-104.

22. Rothemich SF, Woolf SH, Johnson RE, Devers KJ, Flores SK, Villars P, Rabius V, McAfee T. Promoting primary care smoking-cessation support with quitlines: the QuitLink Randomized Controlled Trial. Am J Prev Med 2010;38(4):367-74.

23. Mulder I, Tijhuis M, Smit HA, Kromhout D. Smoking cessation and quality of life: the effect of amount of smoking and time since quitting. Prev Med 2001;33(6):653-60.

\footnotetext{
$* * * * * * * * * * * * * * * * * * * * * *$

Acknowledgements - Nil

Source of Funding - Nil

Conflict of Interest - Nil
} 